Изв. Крымской Астрофиз. Обс. 114, № 1, 101-106 (2018)

\begin{tabular}{c} 
ИЗВЕСТИЯ \\
КРЫМСКОЙ \\
АСТРОФИЗИЧЕСКОЙ \\
ОБСЕРВАТОРИИ \\
\hline
\end{tabular}

УДК 523.945

\title{
Развитие солнечной вспышки из анализа спектральных линий и солнечные космические лучи
}

\author{
И.М. Подгорньйㅁ, А.И. Подгорньй² \\ 1 Институт астрономии РАН, ул. Пятницкая, 48, Москва, Россия \\ podgorny@inasan.ru \\ 2 Физический институт РАН им. П.Н. Лебедева, Ленинский проспект, 53, Москва, Россия \\ podgorny@lebedev.ru
}

Поступила в редакцию 11 ноября 2017 г.

\begin{abstract}
Аннотация. 100-летние исследования космических лучей (КЛ) не привели к пониманию физики ускорения частиц. Ускорение в ударных волнах остается недоказанной гипотезой. Протоны на Солнце ускоряются до энергии $\sim 20$ ГэВ. Вычисленный для ускорения во вспышечном токовом слое в короне и измеренный на нейтронных мониторах спектры совпадают при скорости пересоединения $10^{7} \mathrm{~cm} / \mathrm{c}$. Нет никаких оснований полагать, что механизмы ускорения галактических и солнечных космических лучей различны. Протоны от западных вспышек приходят без столкновений вдоль линии магнитного поля с запаздыванием равным времени пролета. Фотографии в спектральных линиях ионизованного железа показывают образование предвспышечного состояния. Из исследований эмиссии линий высокоионизованных ионов железа следует, что условия для появления вспышки создаются в короне над активной областью, когда численное МГД-моделирование демонстрирует накопление энергии для вспышки над активной областью в токовом слое. Резкое локальное увеличение температуры короны при вспышке до 20 MK демонстрируют спектральные линии 17-18 раз ионизованного железа.

SOLAR FLARE DEVELOPMENT FROM SPECTRAL LINES ANALYSIS AND SOLAR COSMIC RAYS, by I.M. Podgorny and A.I. Podgorny. 100 years of cosmic ray research did not lead to an understanding of particle acceleration physics. Acceleration in shock waves remains an unproved hypothesis. Protons on the Sun are accelerated to the energy of $\sim 20 \mathrm{GeV}$. Calculated for acceleration in the flare current sheet in the corona and the measured on neutron monitors spectra coincide at a reconnection rate of $10^{7} \mathrm{~cm} / \mathrm{s}$. There is no reason to believe that the mechanisms of acceleration of galactic and solar cosmic rays are different. Protons from western flares come without collisions along the magnetic field line with a delay equal to the time of flight. Photos in the spectral lines of the ionized iron show the formation of the pre-flare state. From studies of the emission of highly ionized iron ions it follows that the conditions for the appearance of a flare are created in the corona over an active region when numerical MHD simulation demonstrates accumulation of the energy for a flare over the active region in a current sheet. A sharp local increase in the temperature of the corona during a flare up to $20 \mathrm{MK}$ demonstrates spectral lines 17-18 times of the ionized iron.
\end{abstract}

Ключевые слова: солнечная вспышка, пересоединение, космические лучи, спектральные линии 


\section{1 Введение}

Солнечная вспышка возникает над активной областью (AО), имеющей сложную структуру магнитного поля (Подгорный и др., 2013). Перед вспышкой происходит возрастание магнитного потока АО. Вспышка наблюдается при достижении потоком значения $\sim 10^{22}$ Мкс (Подгорный, Подгорный, 2011). Магнитное поле является единственным резервуаром энергии, реализуемым при вспышке. Во время вспышки не наблюдается каких-либо характерных изменений магнитного поля в АО, что указывает на диссипацию энергии из-за распада токовой системы - токового слоя (ТС), расположенного непосредственно в короне. Численное моделирование вспышки (Подгорный, Подгорный, 2012а, 2012б) при начальных и граничных условиях, заданных из наблюдения эволюции предвспышечного состояния, показало, что в короне над АО формируется ТС, в магнитном поле которого накапливается энергия для вспышки. Образование ТС происходит за счет фотосферных возмущений, фокусирующихся в окрестности особой линии магнитного поля Х-типа. После перехода ТС в неустойчивое состояние возникает взрывное выделение энергии. Рентгеновские измерения еще в 2001 г. (Лин и др., 2003) показали, что выделение энергии $\sim 10^{32}$ эрг происходит на высоте $\sim 2 \times 10^{9}$ см. В короне образуется облако горячей плазмы с концентрацией $\sim 10^{11} \mathrm{~cm}^{-3}$. Несмотря на этот фундаментальный результат, в литературе продолжают появляться работы, в которых источником вспышки является хромосферный жгут (Зайцев и др., 2015). Никаких наблюдательных подтверждений такого процесса не приводится. Особый интерес к вспышкам обусловлен открытием солнечных космических лучей, определяющих резкое изменение космической погоды. Теории происхождения галактических космических лучей чаще всего основаны на никем не доказанных механизмах ускорения ионов в ударных волнах. Независимую информацию о динамике предвспышечного состояния и о происхождении вспышки содержат результаты измерения эмиссий высокоионизованных спектральных линий во время вспышки и в предвспышечном состоянии на аппарате Solar Dynamic Observatory (SDO). Развитие вспышки хорошо просматривается в спектральных линиях $193 \AA$ и $131 \AA$ ионов железа Fe XXIV и Fe XXIII, максимальная яркость которых соответствует электронной температуре $T_{e} \sim 20 \mathrm{MK}$ и $T_{e} \sim 16 \mathrm{MK}$, а появление предвспышечного состояния, позволяющего предсказать появления вспышки, наблюдается в линии $94 \AA$ (Fe XVIII, $T_{e} \sim 6.3$ MK). Эмиссия линий $304 \AA$ (He I, $\left.T_{e} \sim 0.05 \mathrm{MK}\right)$ и $1600 \AA$ (CIV, $\left.T_{e} \sim 0.1 \mathrm{MK}\right)$ дает информацию о динамике плазмы перед вспышкой и во время вспышки на границе хромосферы и короны.

\section{2 Вспышка в центральной части солнечного диска}

На рис. 1 представлены магнитограммы предвспышечного состояния АО 12192 и вспышки Х3.1 24 октября 2014 г., происшедшей в центральной части солнечного диска S12W21. Отчетливо видно удивительное на первый взгляд постоянство распределения магнитного поля во время вспышки. Такое постоянство указывает на диссипацию токов в короне во время вспышки при практически постоянном распределении магнитного поля в АО на фотосфере. Никаких признаков выделения энергии в хромосфере перед вспышкой эмиссия линии $1600 \AA$ не показывает. При возникновении вспышки $(t=21: 18)$ в эмиссии линии $1600 \AA$ видны хромосферные вспышечные ленты, которые долгое время считались основным проявлением солнечной вспышки. Перед вспышкой в спектральной линии $171 \AA\left(T_{e} \sim 0.6 \mathrm{MK}\right)$ часто появляется эмиссия сложной формы, отражающая в основном форму множества линий магнитного поля, однако одновременно с появлением вспышечных лент в линии $171 \AA$ возникает небольшая, но яркая предвспышечная структура. В корональной линии $94 \AA$ отчетливо видно появление перед вспышкой этой яркой предвспышечной структуры. Согласно данным численного МГД-моделирования, медленное образование ТС над АО происходит за счет фокусировки слабых возмущений, приходящих от фотосферы. Возрастающий в короне ток должен нагревать плазму в ТС. Это нагревание плазмы перед вспышкой демонстрирует эмиссия линии $94 \AA$ А․ При вспышке происходит взрывное разрушение ТС и быстрое нагревание плазмы в ТС. Нагревание плазмы во время вспышки показывает кадр $t=21: 30$. Самая высокотемпературная спектральная линия $193 \AA$ $\left(T_{e} \sim 20 \mathrm{MK}\right)$ не показывает яркой предвспышечной структуры. Вспышечное энерговыделение в это 


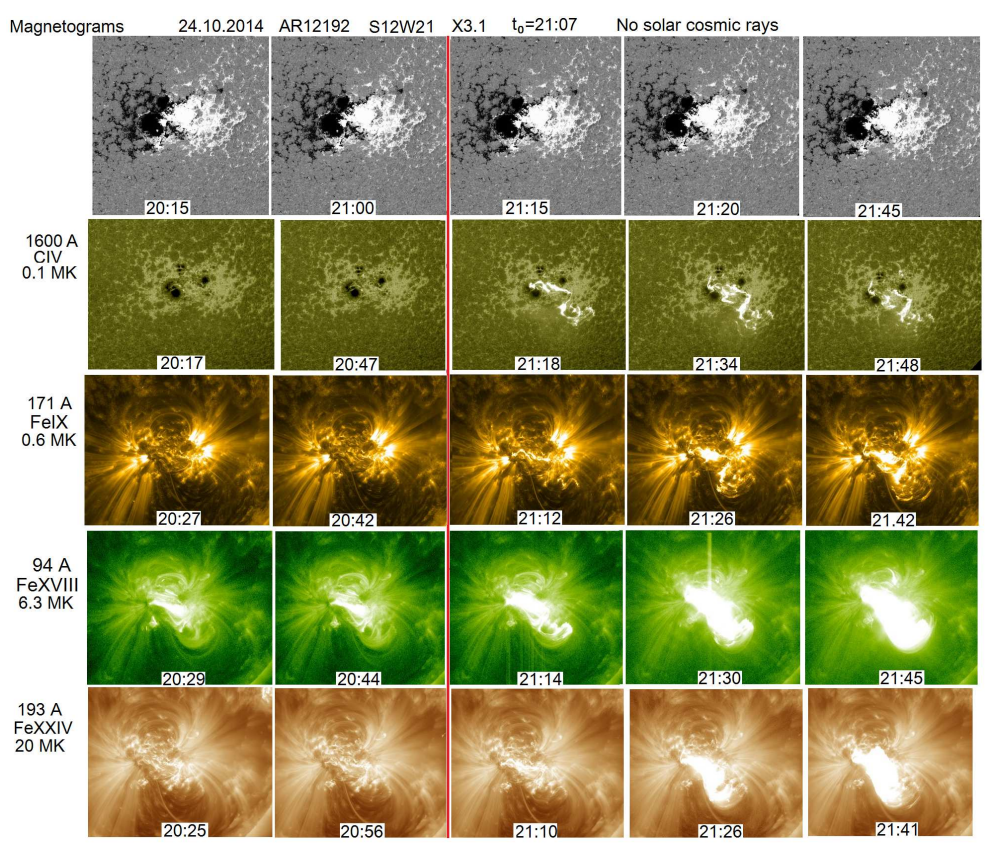

Рис. 1. Магнитограммы и фотографии эмиссии предвспышечного состояния и вспышки ХЗ.1 в УФ спектральных линиях. Вертикальная красная линия разделяет кадры до и после начала вспышки

время еще не началось. Вспышечное выделение энергии начинается $(t=21: 26)$ после старта вспышки. Резкое возрастание яркости эмиссии линии $131 \AA$ происходит из-за диссипации тока ТС при быстром магнитном пересоединении. Таким образом, магнитная энергия перед вспышкой медленно накапливается в короне над АО и быстро выделяется при переходе ТС в неустойчивое состояние. Эти процессы практически незаметны в распределении магнитного поля на фотосфере во временном масштабе порядка одного часа.

Предвспышечное состояние некоторых больших вспышек имеет характерную форму, отличную от других центров эмиссии, не сопровождаемых вспышками. Такое предвспышечное состояние может появляться в спектральной линии $94 \AA$ за десятки часов перед вспышкой класса $\mathrm{X}$ и является удобным признаком для прогноза больших вспышек (рис. 2). Данные численного МГД-моделирования вспышек показали, что развитие предвспышечной структуры всегда происходит одновременно с образованием вспышечного ТС над АО. Температура предвспышечного состояния на два порядка величины превышает температуру хромосферы, но всегда меньше температуры вспышки. Предвспышечное состояние отчетливо наблюдается в спектральной линии, указывающей на температуру $6.3 \mathrm{MK}$, но слабо выражено в эмиссиях, наблюдаемых перед вспышкой при больших температурах ( $\left.T_{e} \geq 16 \mathrm{MK}\right)$. Однако слабая эмиссия в этих линиях перед вспышкой резко возрастает во время вспышки за несколько минут, как это следует из рисунков 1 и 2.

Характерная для предвспышечных состояний структура с температурой 6 MK, наблюдаемых в центре солнечного диска, обнаруживается перед 50 \% больших вспышек. Наблюдаемые проекции этих структур на плоскость, перпендикулярную лучу зрения, не позволяют сделать однозначного суждения о конфигурации предвспышечных структур. Температура предвспышечных структур, превышающая на несколько порядков температуру плотной хромосферы в течение десятков часов, указывает на расположение предвспышечных структур в солнечной короне над $\mathrm{AO}$, а неизменность распределения магнитного поля $\mathrm{AO}$ во время вспышки противоречит возможности поступления энергии во время вспышки из фотосферы. При этом форма отдельных светящихся линий магнитного поля явно не совпадает с наблюдаемой формой предвспышечного свечения. Форма предвспышечной эмис- 


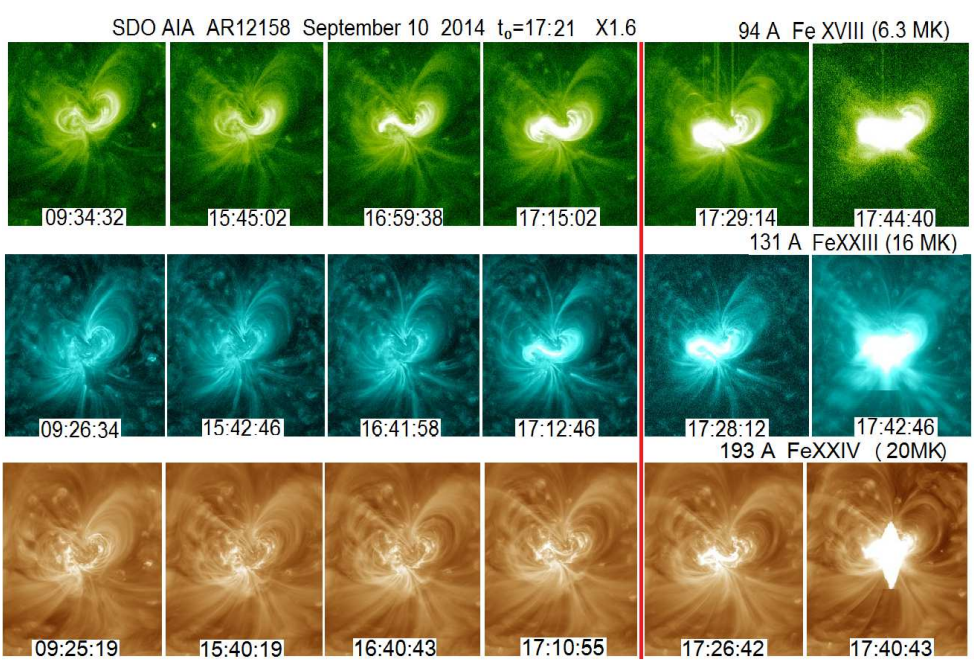

Рис. 2. Предвспышечное состояние и вспышка Х1.6 в линиях $94 \AA$, $131 \AA$ и $193 \AA$. Такая специфическая конфигурация эмиссии линии $94 \AA$ всегда сопровождается большой вспышкой
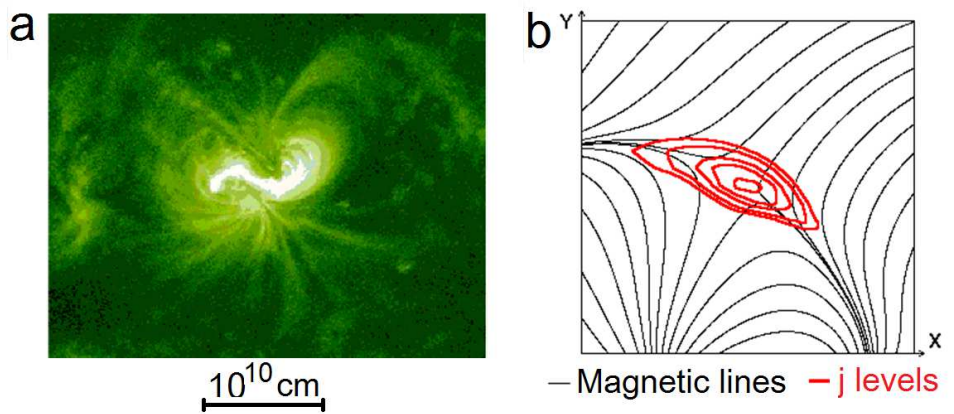

Рис. 3. Предвспышечная структура в спектральной линии $94 \AA$ и линии магнитного поля при начале образования вспышечного ТС согласно данным численного МГД-моделирования. Показаны также линии постоянной плотности тока

сии в увеличенном масштабе представлена на рис. За, а результат вычисления в МГД-моделировании линий магнитного поля и линий уровня электрического тока в начальной стадии образования ТС (Подгорный, Подгорный, 2009) показан на рис. Зб.

\section{3 Предвспышечное состояние и вспышка на лимбе солнечного диска}

На фотографиях вспышек, возникших на западном и восточном лимбах солнечного диска, можно отчетливо наблюдать развитие изображений вспышечных структур за границей диска. Развитие предвспышечной структуры и вспышки M5.1 17 мая 2012 г. над AO 11476 N13W87 в короне отчетливо видно в линиях $94 \AA$ и $193 \AA$ на рис. 4. Аналогичное поведение демонстрируют все большие вспышки, зарегистрированные на западном и восточном лимбах.

Появление эмиссии спектральной линии $94 \AA$ в короне перед вспышкой над солнечным диском отчетливо видно на снимках 23:17 и 01:17. Яркость этих эмиссий в короне возрастает после возникновения вспышки $\left(t_{0}=01: 25\right)$. Высокотемпературная спектральная линия $193 \AA\left(T_{e} \sim 20 \mathrm{MK}\right)$ в предвспышечном состоянии показывает слабое свечение на краю диска (стрелка на снимке 23:15), но 


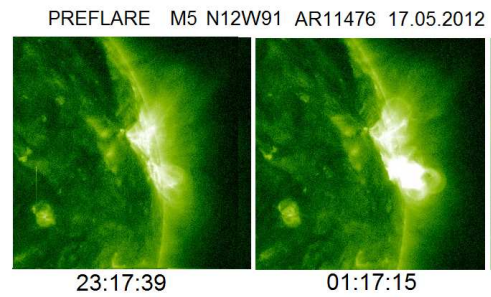

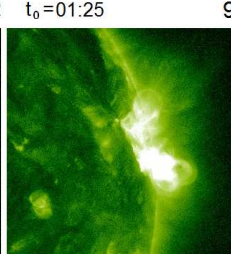

$01: 32: 39$

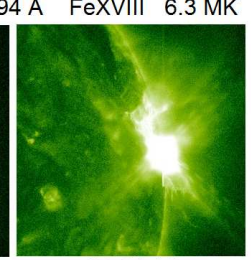

02:01:15

193 A FeXXIV $20 \mathrm{MK}$

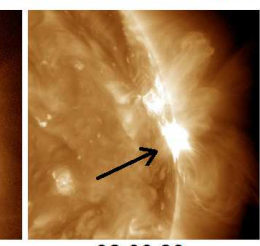

02:00:20

Рис. 4. Предвспышечное состояние и вспышка на западном лимбе солнечного диска в спектральных линиях $94 \AA$ и $193 \AA$

она ярко вспыхивает в короне на снимке, снятом после старта вспышки (стрелка на снимке 02:00). Из рис. 4 отчетливо следует, что накопление энергии и быстрое развитие вспышки происходит в короне над солнечным диском. Вспышка не является хромосферным явлением.

\section{4 Распространение солнечных космических лучей}

Повышенный интерес к солнечным вспышкам в значительной степени возрос в связи с возможностью детально исследовать механизм их генерации и распространения в межпланетном пространстве. Дело в том, что открытие космических лучей и их столетнее исследование многочисленными научными коллективами не привело к выяснению механизма их генерации. Наиболее популярная идея ускорения космических лучей ударными волнами не подтверждена наблюдениями и остается не более чем рабочей гипотезой. С открытием солнечных космических лучей с энергией 20 ГэВ появилась возможность проведения прямых исследований механизма ускорения и распространения частиц высокой энергии в космосе, а следовательно, понимания происхождения космических лучей, т. к. нет никаких оснований предполагать существование различных механизмов ускорения частиц в галактиках и на Солнце. В работе (Подгорный и др., 2010) показано, что экспоненциальный спектр протонов, приходящих на фронте потока, совпадает с вычисленным спектром протонов, ускоренных в ТС, распад которого вызвал вспышку.

Появление каждого импульса солнечных космических лучей связано с конкретной большой вспышкой (класса X или $\mathrm{M}$ ), однако не каждая большая вспышка сопровождается потоком релятивистских протонов. Типичные потоки протонов на орбите Земли, сопровождающие вспышки, происшедшие на западной и восточной частях солнечного диска, показаны на рис. 5. Западные вспышки сопровождаются анизотропным потоком протонов с крутым фронтом и запаздывающим относительно старта вспышки не более чем на 20 мин. Это значит, что поток протонов распространяется без столкновений вдоль линий магнитного поля спирали Архимеда. Затем следует диффузионный поток с изотропным распределением скоростей, длящийся около 3-х суток. По-видимому, поток протонов на фронте вызывает развитие пучковой неустойчивости. Длительность потока ускоренных протонов, регистрируемых на орбите Земли, составляет 2-3 суток, в то время как длительность $\gamma$-излучения, вызванного попаданием ускоренных протонов на Солнце, соизмерима с длительностью вспышки (20-50 мин), оцененной по тепловому рентгеновскому излучению. Большая длительность регистрируемого у Земли потока протонов может определяться только диффузией. 

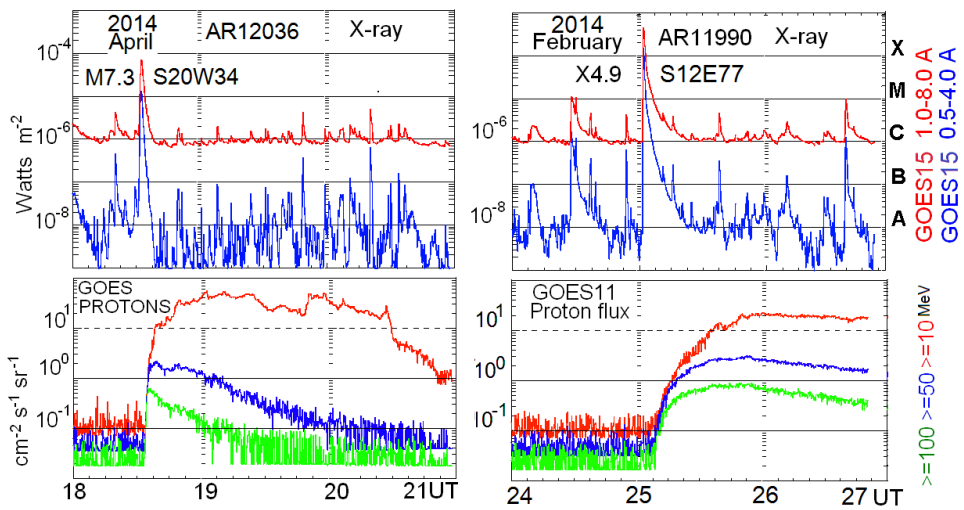

Рис. 5. Развитие вспышек, происшедших на восточной и западной частях солнечного диска и солнечных космических лучей, зарегистрированных аппаратом GOES

Распространение ускоренных протонов от восточных вспышек может происходить только поперек линий межпланетного магнитного поля за счет диффузии. Диффузионный фронт потока протонов превышает 10 часов (рис. 5), а типичное запаздывание прихода фронта к Земле около 3-х часов.

\section{5 Заключение}

Анализом эмиссий спектральных линий высокоионизованных ионов исследована динамика температуры в предвспышечном состоянии и во время вспышек. Предвспышечная структура иногда появляется над $\mathrm{AO}$ за 10-30 часов перед вспышкой. Наиболее яркое изображение предвспышечной структуры наблюдается в излучении спектральной линии Fe XVIII $94 \AA$ А, соответствующей температуре 6.3 MK. Появление предвспышечной структуры совпадает с генерацией ТС и накоплением магнитной энергии в короне для вспышки, которое показано в численном МГД-моделировании. Структура эмиссии линии имеет специфическую форму, отличную от центров эмиссии, наблюдаемых на солнечном диске, но не вызвавших вспышки. Во время вспышки яркость эмиссии линии $94 \AA$ возрастает. Очень резкое (взрывное) возрастание яркости эмиссии показывает линия $131 \AA$ (Fe XXIII, $T \sim 16 \mathrm{MK}$ ) и особенно линия $193 \AA$ (Fe XXIV, $T_{e} \sim 20$ MK), демонстрирующие нагревание облачка плазмы в короне при вспышке. Выделение тепловой энергии в короне за пределами границы солнечного диска на высоте $\sim 2 \times 10^{9}$ см демонстрируют фотографии вспышечных событий на лимбе солнечного диска. Накопление энергии для вспышки и вспышка происходят в солнечной короне. Нет никаких оснований связывать происхождение вспышки с хромосферой. Солнечные космические лучи генерируются во вспышке, и их распространением к Земле управляет межпланетное магнитное поле.

\section{Литература}

Зайцев В.В. и др. // XIX Всероссийская ежегодная конференция по физике Солнца “Солнечная и солнечно-земная физика - 2015”. СПб: ГАО РАН. 2015. С. 149.

Лин и др. (Lin R.P. et al.) // Astrophys. J. 2003. V. 595. P. 76.

Подгорный, Подгорный (Podgorny A.I., Podgorny I.M.) // Proc. 32th Ann. Apatity Sem. 2009. P. 123.

Подгорный и др. (Podgorny I.M. et al.) // JASTP. 2010. V. 72. P. 988.

Подгорный А.И., Подгорный И.М. // Астрон. журн. 2011. Т. 88. С. 684.

Подгорный А.И., Подгорный И.М. // Геомагн. Аэрон. 2012а. Т. 52. С. 163.

Подгорный А.И., Подгорный И.М. // Геомагн. Аэрон. 2012б. Т. 52. С. 167.

Подгорный и др. (Podgorny I.M. et al.) // Sun Geosphere. 2013. V. 8. P. 63. 